\title{
Experimental evidence for coffinite formation from $\mathrm{UO}_{2+\mathrm{x}}$
}

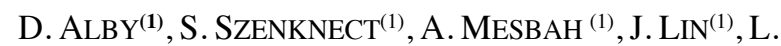
DURO $^{(2)}$, M. LÓPEZ-GARCÍA ${ }^{(2)}$, L. Z. EVINS ${ }^{(3)}$, C. WANG, R. C. EWING ${ }^{(4)}$, N. DACHEUX ${ }^{(1)}$ AND J. BRUNO $^{(2) *}$

${ }^{1}$ ICSM, CEA, CNRS, ENSCM, Univ Montpellier, Site de Marcoule - Bât. 426, 30207, Bagnols-sur-Cèze, France. [stephanie.szenknect@cea.fr]

2 AMPHOS 21, Amphos 21 Consulting SL, carrer Veneçuela 103, 08019, Barcelona, Spain[*correspondenc,jordi.bruno@amphos21.com]

${ }^{3}$ The Swedish Nuclear Fuel and Waste Management Company (SKB), Box 3091, 16903 Solna, Sweden[lena.z.evins@skb.se]

${ }^{4}$ Department of Geological Sciences, Stanford University, Stanford, CA 94305-2115

USA[rewing1@stanford.edu]

In previous work $[1,2]$ the synthesis of coffinite, has been investigated and its thermodynamic stability established. The key findings are that coffinite can form in anoxic conditions, at alkaline $\mathrm{pH}$ and in silica-rich solutions and that coffinite is metastable with respect $\mathrm{UO}_{2}$ (cr).

We have investigated the pathways for the formation of coffinite from $\mathrm{UO}_{2}$ at alkaline $\mathrm{pH}$, in the presence of silica-rich solutions under anoxic conditions. This has been done by a combination of solution chemistry, spectrophotometric and electron microbeam techniques (SEM and TEM). The results demonstrate that coffinite forms from $\mathrm{UO}_{2+\mathrm{x}}$ at surface layers under these conditions.

1.Xiaofeng Guo et al (2015) Thermodynamics of formation of coffinite, $\mathrm{USiO}_{4}$. Proceedings of the National Academy of Sciences, vol. 112, 6551-6555, doi: 10.1073/pnas. 1507441112 .

2.Stephanie Szenknect, et al (2016) First experimental determination of the solubility constant of coffinite. Geochimica Cosmochimica Acta, vol. 181, 36 - 53. 